\title{
PROGNOSIS AND TREATMENT OF ACUTE DIFFUSE PERITONITIS IN CHILDREN SINCE THE ADVENT OF CHEMOTHERAPEUTIC DRUGS
}

\author{
BY \\ KENNETH M. ALFORD, M.D.
}

For the past few years the paediatric and surgical literature has contained numerous articles on methods of treating cases of peritonitis in children in an effort to bring down the high mortality rate. Most of these articles have been specially concerned with peritonitis following acute appendicitis with perforation, and both the conservative school which bases treatment on Ochsner's (1902) original plan and the school which believes in early operation, as described first by Blake (1903), report remarkably low mortality figures. An analysis of all the cases of acute diffuse peritonitis that have come into, or developed in, the medical and surgical wards of the Hospital for Sick Children, Toronto, since 1935 shows an appalling death-rate. Sixty per cent. of cases died. When these deaths are plotted on a graph with each year's mortality rate noted separately, a dramatic drop in the mortality figures appears to have taken place in the past two years. It is the purpose of this paper to analyse these cases of peritonitis and find out in what respects the treatment has been altered so as to bring about this more favourable prognosis.

For the purpose of simplifying the classification of these cases they have been divided into two groups: (1) primary or idiopathic peritonitis, and (2) secondary peritonitis, rather than classified under their respective causative pyogenic organisms. The primary group includes infections extending from the navel in the newborn or sepsis neonatorum involving the peritoneum: infections by the blood stream with organisms carried to the peritoneum from a distant focus such as the throat, ear, lungs, or joints: lymphatic invasion: or infections from the genito-urinary tract. The seccrdary group includes the intra-abdominal catastrophes with perforation of the bowel as a result of trauma, infection, peptic ulcer, congenital abnormality or the conditions which interfere with the blood supply of the bowel.

With these two main groups in mind, table 1 represents the yearly mortality rate for all cases of diffuse peritonitis that have been admitted to the hospital since 1935. These figures are shown graphically in fig. 1 . It is shown that since January 1, 1939, all types of peritonitis, whether primary or secondary, have responded to hospital care much more efficiently than previously, since 
they have been given large doses of sulphanilamide and sulphapyridine, depending on the nature of the causative organism.

$$
\text { Mortalitr Rate of Acute Dirfuse Peritovitis }
$$

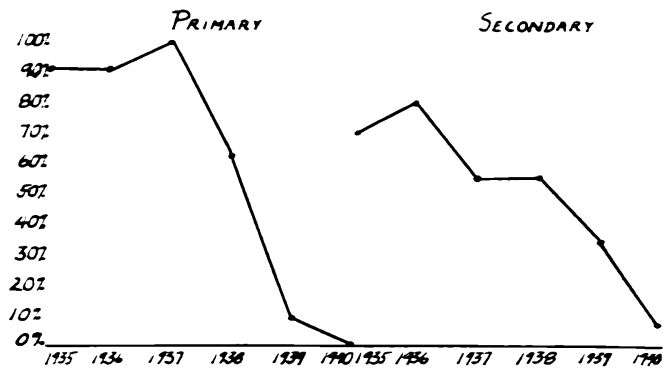

FIG. 1.

TABLE 1

MORTALITY RATE OF ACUTE DIFFUSE PERITONITIS

\begin{tabular}{|c|c|c|c|c|c|c|}
\hline \multicolumn{4}{|c|}{ Primary } & \multicolumn{3}{|c|}{ SECONDARY } \\
\hline YEAR & Cases & Deaths & $\begin{array}{c}\text { Percentage } \\
\text { Mortality }\end{array}$ & Cases & Deaths & $\begin{array}{l}\text { Percentage } \\
\text { Mortality }\end{array}$ \\
\hline $\begin{array}{l}1935 \\
1936 \\
1937 \\
1938 \\
1939 \\
1940\end{array}$ & $\begin{array}{r}24 \\
12 \\
10 \\
8 \\
11 \\
2\end{array}$ & $\begin{array}{r}22 \\
11 \\
9 \\
5 \\
1 \\
0\end{array}$ & $\begin{array}{c}91 \cdot 6 \\
91 \cdot 6 \\
100 \\
62 \cdot 5 \\
9 \\
0\end{array}$ & $\begin{array}{r}20 \\
20 \\
20 \\
7 \\
23 \\
13\end{array}$ & $\begin{array}{r}14 \\
16 \\
11 \\
4 \\
8 \\
1\end{array}$ & $\begin{array}{l}70 \\
80 \\
55 \\
55 \\
34 \cdot 7 \\
7 \cdot 6\end{array}$ \\
\hline Total & 67 & 48 & $71 \cdot 6$ & 103 & 54 & $52 \cdot 4$ \\
\hline
\end{tabular}

For the purpose of discussing treatment, primary peritonitis will be subdivided into streptococcal peritonitis and pneumococcal peritonitis, as these are by far the most common causative organisms (table 2).

TABLE 2

\section{CAUSATIVE ORGANISMS IN PRIMARY PERITONITIS}

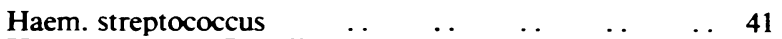

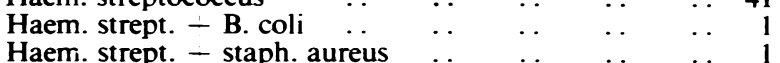

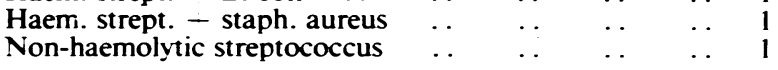

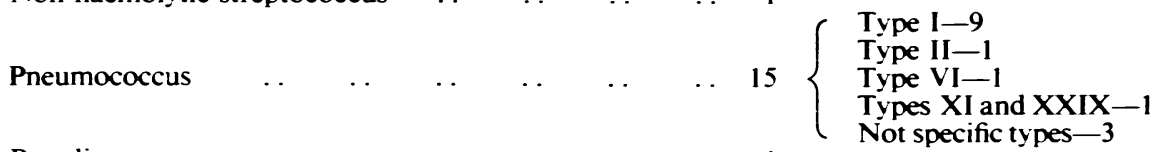

B. coli

$\begin{array}{lllllll}\ddot{\text { Staphylococcus aureus }} & \ldots & \ldots & \ldots & \ldots & \ldots & 1\end{array}$

\section{Primary peritonitis}

In determining the type of primary peritonitis from a bacteriological standpoint, only eleven vaginal smears were taken, none of which was positive 
for pneumococcus, so that clinically the classical primary pneumococcal peritonitis described by Mechant (1901) could not be diagnosed in this series. There were twenty throat swabs taken, fourteen of which were positive and checked with five positive blood cultures. There were fifty-four blood cultures taken in the group with twenty-nine positive. Peritoneal fluid was obtained and cultured only twenty-nine times while the child was alive and gave the causative organisms in twenty-eight of these cases. Fortunately thirty-one out of forty-eight post-mortem examinations were obtained, so that it was possible not only to check the accuracy of the clinical bacteriological findings but also to determine the type of organism present when the peritoneal fluid was not obtained before death. The importance of obtaining peritoneal fluid, either by inserting the 17-standard wire gauge short bevel needle with a dull point into the peritoneal cavity or by doing a surgical exploration under local anaesthesia, to determine the nature of the offending organism is emphasized here because the result of the finding determines the subsequent method of therapy.

In the cases of streptococcal peritonitis approximately 75 per cent. of the cases were associated with an upper respiratory infection, such as rhinitis, pharyngitis, tonsillitis, otitis media and mastoiditis. The remainder were associated in four instances with erysipelas, one complicating scarlet fever and one measles; one case was associated with nephrosis and one with streptococcal suppurative arthritis and osteomyelitis. In the pneumococcal group it was harder to find an etiological background, but 50 per cent. were associated with upper respiratory infections and the other 50 per cent. could not be determined.

The average age incidence for primary peritonitis was three years and ranged between three-and-a-half hours and eleven years. Twenty-seven of the cases were infants under two years of age and in this group twenty-four died, a mortality rate of 88.8 per cent. The three infants that lived all recovered in the past year on chemotherapeutic drugs. There were a few more female children suffering from this disease than males ( 56.7 per cent.). The important signs and symptoms were similar in both the pneumococcal and streptococcal varieties of peritonitis. The children suffered from vomiting, abdominal pain and diarrhoea, and in the infant group the mother almost invariably stated that the child had colic, abdominal tenderness and irritability. The temperature on admission averaged $103^{\circ} \mathrm{F}$., varying between $97^{\circ}$ and $106 \cdot 2^{\circ}$. The average leucocyte count was 19,000 per c.mm., varying between 3,700 and 138,000; the latter was a case complicated by broncho-pneumonia. The average number of polymorphonuclear granulocytes was 75 per cent., with a variation between $\mathbf{4 0}$ per cent. and 98 per cent. On physical examination all the children appeared acutely ill, with considerable amount of abdominal tenderness and distension. In 75 per cent. of the streptococcal and 50 per cent. of the pneumococcal infections other evidence of disease could be found in either the ear, nose, throat, skin, joints or chest.

In discussing the treatment of these cases in relation to the mortality rate it is proposed to start at the beginning of the present series. In 1935, two cases recovered. Both were of the pneumococcal variety. One was a type II 
pneumococcus peritonitis who received nothing specific, but recovered after running a stormy course for one month. The other recovery received 60,000 units of type I anti-pneumococcal horse serum intravenously. In 1936 there was one recovery also of pneumococcal type I origin. He recovered on the administration of 260,000 units of anti-pneumococcal horse serum. All in the 1937 series succumbed. One was removed by the parents when acutely ill. Six haemolytic streptccoccal and two pneumococcal infections received no specific therapy. Two children received sulphanilamide and died. One was given 15 grains of sulphanilamide before death, which was three hours after being admitted to hospital, and the other received an insufficient dose of sulphanilamide as it is now calculated in accordance with the resulting blood levels. This was during the early experimental stage with these drugs, and prontosil was given intravenously along with the sulphanilamide by mouth. with a resulting deep red pigmentation of the skin and mucous membrane.

In 1938 there were five cases of haemolytic streptococcal infection. Four died. Two of these received no chemotherapy and two who received sulphanilamide were young infants. One, four weeks of age, who received an adequate dose (2 to 3 grains per pound of body weight in twenty-four hours). but was only able to concentrate in the blood up to $1.4 \mathrm{mgm}$. per cent. A six-weeks-old infant had an insufficient dose of sulphanilamide plus the intravenous administration of prontosil, and showed no response to either drug. One child recovered on 1 grain of sulphanilamide per pound of body weight over a period of two weeks with a blood concentration of $3.9 \mathrm{mgm}$. per cent. There were also three cases of pneumococcal infection. The one who died had a type VI infection and received no specific therapy. The two who recovered were both due to type I pneumococcus and were given large doses of antipneumococcal rabbit serum, and one of the two in addition received sulphanilamide by mouth.

In 1939 there were nine cases of haemolytic streptococcal peritonitis with eight recoveries. Six received adequate doses of sulphanilamide: one started on sulphanilamide, but, as he did not respond, was changed to sulphapyridine and subsequently recovered: and one received sulphapyridine alone. The children on sulphanilamide received $1 \frac{1}{2}-3$ grains of the drug per pound of body weight per day from nine to twenty-seven days with an average of $9 \cdot 3 \mathrm{mgm}$. per cent. concentration in their blood. The ten-months-old girl on sulphapyridine received 3 grains per pound for eight days and then the dose was cut to $1 \frac{1}{2}$ grains per pound for ten days. The boy that died was a case of streptococcal peritonitis who was put on adequate doses of sulphapyridine and soludagenan for eighteen days before sulphanilamide was tried, and then only for twenty-four hours. He was then changed back to soludagenan because of persistent vomiting. He had an average sulphapyridine concentration of $10 \cdot 1 \mathrm{mgm}$. per cent. in the blood stream, but went on to develop pneumonia and empyema and finally died. It has been our opinion in the Toronto clinic that children suffering from streptococcal infections do better on sulphanilamide and those from pneumococcal better on sulphapyridine. If this boy were again to come under our care sulphanilamide would have been started at the beginning. 
and then if there had been no response sulphapyridine and soludagenan begun. Of four cases of pneumococcal peritonitis who recovered, two of type I received antipneumococcal rabbit serum plus sulphapyridine. A third child with type XI and type XXIX pneumococcus and one with an untypable pneumococcus made good recoveries on adequate doses of sulphapyridine alone. These children received between 1 and $1 \frac{1}{2}$ grains sulphapyridine per pound of body weight and maintained an average concentration of $4.4 \mathrm{mgm}$. in the blood stream.

The present treatment for primary peritonitis in children as a result of our experience with the chemotherapeutic drugs is outlined in table 3.

TABLE 3

\section{PRESENT TREATMENT FOR PRIMARY PERITONITIS IN CHILDREN}

1. Obtain peritoneal fluid on admission to determine specific organism.

2. Check above by blood culture, sputum examination (Auger method), and vaginal culture.

3. Fowler's position.

4. Light cradle to abdomen.

5. Continuous intravenous administration of fluids, in infants, $2 / 3$ glucose in distilled water - 13 normal saline: older children, 5 to 10 per cent. glucose in normal saline.

6. Type child and have donor ready to give transfusion if haemoglobin or white blood-cells drop following the administration of chemotherapeutic drug, or if serum protein falls following continuous intravenous fluids.

7. For streptococcal infection-sulphanilamide, 2 to 3 grains per lb. body weight in twentyfour hours until the concentration in blood reaches $10 \mathrm{mgm}$. per cent. and then cut down to 1-1 $\frac{1}{2}$ grain per lb. body weight until temperature remains normal for two to three days and clinically child is cured.

8. For pneumococcal infections-sulphapyridine, 1 to 2 grains per lb. body weight in twentyfour hours until concentration in blood reaches $4-5 \mathrm{mgm}$. per cent. and then continue with 1 grain per lb. until temperature remains normal for two to three days and clinically child is improved.

In addition 100,000-200,000 units of type specific antipneumococcal rabbit serum.

\section{Secondary peritonitis}

Secondary peritonitis, classified above, presents chiefly a surgical problem, the most important aspect of which concerns acute appendicitis with perforation, which I do not feel qualified to discuss. The statistics of these cases raised some interesting problems. The mortality rate, as in primary peritonitis, has made an appreciable drop, although more gradually than in the first group (table 4), the best results, obtained in the past year, having followed combined

TABLE 4

MORTALITY RATE COMPARING SECONDARY PERITONITIS WITH APPENDICEAL PERITONITIS

\begin{tabular}{|c|c|c|c|c|c|c|}
\hline \multicolumn{4}{|c|}{ SECONDARY } & \multicolumn{3}{|c|}{ APPENDICEAL } \\
\hline YEAR & CASES & DEATHS & $\begin{array}{l}\text { MORTALITY } \\
\text { PER CENT. }\end{array}$ & CASES & DEATHS & $\begin{array}{l}\text { MORTALITY } \\
\text { PER CENT. }\end{array}$ \\
\hline $\begin{array}{l}1935 \\
1936 \\
1937 \\
1938 \\
1939 \\
1940\end{array}$ & $\begin{array}{r}20 \\
20 \\
20 \\
7 \\
23 \\
13\end{array}$ & $\begin{array}{r}14 \\
16 \\
11 \\
4 \\
8 \\
1\end{array}$ & $\begin{array}{l}70 \\
80 \\
55 \\
55 \\
34.7 \\
7.6\end{array}$ & $\begin{array}{r}14 \\
13 \\
16 \\
5 \\
19 \\
12\end{array}$ & $\begin{array}{r}9 \\
10 \\
7 \\
2 \\
4 \\
0\end{array}$ & $\begin{array}{r}64 \\
76 \\
43 \\
40 \\
21 \\
0\end{array}$ \\
\hline
\end{tabular}


surgical treatment with the use of chemotherapeutic drugs. This method of treatment has already been reported by Ravdin, Rhoads and Lockwood (1940) who used sulphanilamide in cases of peritonitis following ruptured appendix after they had found in experimental animals that sulphanilamide diffuses readily into the peritoneal fluid. Clinically they found that their recoveries did not run the stormy course which they had done prior to the use of the drug.

The cases of secondary peritonitis in the present series were due to the associated diseases shown in table 5 , and the causative organism is shown in table 6.

TABLE 5

\section{CAUSES OF SECONDARY PERITONITIS}

1. Acute appendicitis with perforation

2. Perforation of the bowel associated with:

a. Meckel's diverticulum

b. Volvulus

c. Ulceration of the bowel

d. Strangulation of the bowel

e. Necrosis and gangrene of the stomach

f. Duodenal ulcer

g. Trauma

h. Congenital malformations

3. Acute enteritis and intestinal intoxication

4. Post-operative appendicectomy

5. Post-operative gastrostomy ..

6. Post-operative gastro-enterostomy .

7. Questionable ..

\begin{tabular}{|c|c|c|c|c|c|c|}
\hline$\cdots$ & $\cdots$ & $\cdots$ & $\cdots$ & $\cdots$ & $\cdots$ & 79 \\
\hline . & . & . & . & $\cdots$ & $\cdots$ & \\
\hline . & . & . & . & $\ldots$ & $\ldots$ & \\
\hline . & . & . & . & $\cdots$ & $\ldots$ & \\
\hline . & $\cdots$ & . & . & $\cdots$ & $\ldots$ & \\
\hline$\cdots$ & $\cdots$ & .. & .. & $\cdots$ & $\cdots$ & 113 \\
\hline$\cdots$ & $\cdots$ & - & - & $\cdots$ & $\cdots$ & \\
\hline$\cdots$ & $\cdots$ & $\cdots$ & $\cdots$ & $\cdots$ & $\cdots$ & \\
\hline$\cdots$ & . & . & . & $\cdots$ & $\cdots$ & \\
\hline$\cdots$ & $\cdots$ & - & $\cdots$ & $\cdots$ & $\cdots$ & \\
\hline$\cdot$ & $\cdots$ & $\cdots$ & $\cdots$ & $\cdots$ & $\cdots$ & 2 \\
\hline & $\cdots$ & $\cdots$ & $\cdots$ & $\cdots$ & $\cdots$ & $\frac{1}{1}$ \\
\hline$\cdots$ & . & $\cdots$ & . & $\cdots$ & $\cdots$ & \\
\hline 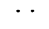 & . & . & $\cdots$ & $\cdots$ & $\ldots$ & 4 \\
\hline
\end{tabular}

\section{TABLE 6}

\section{CAUSATIVE ORGANISMS IN THE CASES OF SECONDARY PERITONITIS}

$\begin{array}{lrrrr}\text { B. coli .. . } & \ldots & \ldots & 57 \\ \text { B. coli and enterococcus } & \ldots & 3 \\ \text { B. coli and haem. strept... } & \ldots & 2 \\ \text { B. coli and staphylococcus aureus } & 1 \\ \text { Enterococcus } & \ldots & \ldots & \ldots & 1 \\ \text { Haem. strept. } & \ldots & \ldots & \ldots & 3 \\ \text { B. pyocyaneus } & \ldots & \ldots & \ldots & 2 \\ \text { Pneumococcus type XIV .. } & \ldots & 1 \\ & \text { TOTAL } & \ldots & 70\end{array}$

The age incidence was on an average higher than the primary group, being $7 \cdot 7$ years, ranging from twenty months to thirteen years, with the sex being 65 per cent. males as compared with 35 per cent. females. The highest mortality rate was also confined to the infants under two years of age, with fifteen deaths out of sixteen cases, or a mortality rate of over 90 per cent.

The signs and symptoms as well as the diagnosis of appendiceal peritonitis are just as important to the paediatrician and general practitioner as they are to the surgeon, because if he diagnoses the case early and has it operated on immediately, the most important measure in therapy has been accomplishedthat is, prevention. The early cases of peritonitis with a ruptured appendix gave a history of abdominal pain which usually was epigastric or umbilical in type but occasionally was localized in the right lower quadrant. The pains 
were often vague and unreliable, especially in the younger age group, and were usually accompanied with or followed by vomiting. The results of the physical examination, which requires patience on the part of the examiner and ability to obtain the child's confidence, were difficult to assess, but palpation of the abdomen usually showed tenderness and occasionally spasm. The diagnosis of these cases was often not made until the peritoneal cavity was opened at operation. Unfortunately many of the cases included in this series were characterized by the anxious, hollow-eyed, shocked child who appeared similar to the younger child suffering from primary peritonitis. The averagè temperature on admission of this group was $101 \cdot 3^{\circ} \mathrm{F}$. and ranged between $98^{\circ}$ and $105^{\circ}$. The white blood-count averaged 15,100 per c. mm. ranging between 4,000 and 30,000. The average number of polymorphonuclear granulocytes was 75 per cent.

The treatment of these cases consisted of the usually accepted measures which from time to time have been added to the treatment in order to bring down the high mortality rate. Practically all the children were put in Fowler's position depending on their age. The older children were put in high or semiFowler's, and the younger children, who do not maintain this position well, were put in low-Fowler's in a gatch-frame bed. Most of them received external heat to the abdomen, usually in the form of a light cradle but also by means of stupes or linseed poultices. Codeine and morphine were the sedatives of choice and were used in large enough doses to control pain, activity and nausea. The water balance was maintained in the majority of these cases by the continuous administration of two-thirds 5 per cent. glucose in distilled water with one-third normal saline in the infant group, a mixture which was found ideal for this purpose; and the older children received an adequate amount of intravenous 5 per cent. to 10 per cent. glucose in normal saline. In those patients in whom vomiting and distension was a disturbing element, a duodenal tube was passed and a continuous duodenal decompression set up as devised by Wangensten (1937). During the past year, under the direction of Dr. D. E. Robertson, this method has been supplemented successfully by the introduction of the Miller-Abbott tube for continuous decompression of the small bowel. All the requirements of Wright, Aaron, Regan and Milch (1939) in their management of sixty cases of diffuse peritonitis in adults and children with a mortality rate of 11.7 per cent., were fulfilled except the routine administration of blood, which they use to increase volume of the circulating blood, to attempt to restore the blood pressure in the shocked child and to supply blood to the peripheral tissues. Only eleven of the first cases received transfusions, mainly as an emergency measure.

In this hospital with several surgical services both the immediate surgical intervention and the conservative treatment have been tried. The literature contains favourable reports from both groups. Ladd (1938) and Elman (1938) are in favour of immediate operation as soon as the child's dehydration and shock have been successfully combated; while Coller and Potter (1934), and Adams and Bancroft (1938) follow a conservative method of therapy with modifications of the original Ochsner's treatment.

In this series fifty-one cases with peritonitis associated with perforated $\mathbf{E}$ 
appendix were operated on at the time of, or shortly after, admission. Fortyfive of these cases were drained while six were closed. Twenty-eight cases received conservative treatment. In the operative group there were thirteen deaths, or a mortality rate of 25 per cent., whereas in the conservative group the mortality rate was 67 per cent. These figures may explain the gradually decreasing mortality rate of the past few years, the only difference in treatment being that more children were operated on early and fewer treated conservatively. In the past two years twenty-five cases were operated on early and only six treated by conservative measures.

A marked drop in mortality figures has been experienced since January. 1940, and although only twelve patients have been admitted with diffuse peritonitis they have all recovered in spite of age, method of operative procedure or seriousness of their general condition on admission. The only additions to the former therapy were the administration of the chemotherapeutic drugs, and in three cases a Miller-Abbott tube was passed because of marked distension. Among the twelve cases, ten received chemotherapeutic drugs, eight as a postoperative measure following early operation and two along with conservative treatment of the disease. Eight of the ten cases were given soludagenan intravenously from one to seven days until they were able to take the drug by mouth and then they were changed to sulphapyridine if their temperature and clinical findings had not entirely subsided. They remained on sulphapyridine from two to seven days. Five of these cases grew b. coli in the peritoneal fluid. One case received soludagenan for two days and was subsequently changed to sulphanilamide for six more days because haemolytic streptococcus as well as b. coli was cultured from the peritoneum. One of the conservatively treated cases received adequate doses of sulphanilamide and recovered.

In 1939 four cases received chemotherapy. Two were given sulphapyridine, one recovered, one died. The recovery was associated with a type XIV pneumococcus infection. The boy who died with a $\mathrm{b}$. coli peritonitis was extremely ill post-operatively, and even though his blood reached a sulphapyridine concentration of $12.1 \mathrm{mgm}$. per cent. and he was kept continuously decompressed by the Miller-Abbott tube, he did not respond and died. The two other children were given sulphanilamide. The child who recovered had a haemolytic streptococcus in the peritoneal fluid and made an uneventful recovery post-operatively. The third child, who died, had a b. coli infection and did not respond to sulphanilamide because only one dose was given prior to his death eight hours after operation.

\section{Conclusions}

From the survey on appendiceal peritonitis it is felt that the mortality rate has been appreciably cut down by the use of the chemotherapeutic drugs just as it was in the cases of primary peritonitis. There is no question that the best method of treatment in these cases is to diagnose the acute appendicitis before rupture. However, in the practice of a children's hospital, neglected cases in which the parents have not called in a physician until after perforation, in which 
the indiscriminate use of laxatives and cathartics has been made for the treatment of abdominal pain, and in which acute appendicitis has been missed, will continue to be admitted. Chemotherapy, although it will not take the place of any of the surgical measures previously mentioned, has proved to be another weapon in the armamentarium against appendiceal peritonitis as well as a specific for primary streptococcal and pneumococcal peritonitis.

\section{REFERENCES}

Adams. J. M., and Bancroft, P. M. (1938). J. Pediat., 12, 293.

Blake, J. A. (1903). Ann. Surg., 38, 265.

Coller. F. A., and Potter, E. B. (1934). J. Amer. med. Ass., 103, 1753.

Elman, R. (1938). Amer. J. Digest. Dis., 5, 804.

Fowler, G. R. (1900). Med. Rec., 57, 617.

Ladd, W. E. (1938). New Engl. J. Med., 219, 329.

Mechant, (19J1). Thèse de Paris.

Ochsner, A. J. (1902). Amer. J. Surg. Gınec., 15, 84.

Ravdin, I. S., Rhoads, J. E.. and Lockwood, J. S. (1940). Ann. Surg., 3, 53.

Wangensten, O. H. (1937). A Therapeutic Problem in Bowel Obstruction, Springfield, Ill.

Wright, T., Aaron, A. H., Regan, J. S., and Milch, E. (1939). J. Amer. med. Ass., 113,1285. 